\title{
The Impact of National Health Insurance Coverage on Compliance With Positive Airway Pressure Therapy in Patients With Obstructive Sleep Apnea
}

\author{
Woori Choi' (i] $\cdot$ Mirye Bae ${ }^{2}$ (i) $\cdot$ Yoosam Chung ${ }^{2}$ (i) \\ ${ }^{1}$ Department of Otorhinolaryngology-Head and Neck Surgery, Samsung Changwon Hospital, Sungkyunkwan University School of Medicine, \\ Changwon; ${ }^{2}$ Department of Otorhinolaryngology-Head and Neck Surgery, Asan Medical Center, University of Ulsan College of Medicine,
}

Seoul, Korea

Objectives. Compliance with positive airway pressure (PAP) in patients with obstructive sleep apnea (OSA) directly affects its treatment efficacy. Since July 2018, polysomnography and PAP therapy have been covered by the National Health Insurance (NHI), which has reduced the price barrier and promoted PAP therapy in Korea. This study aimed to compare changes in PAP compliance before and after NHI implementation.

Methods. This study is a retrospective analysis in a tertiary hospital setting in Korea. From 2011 to 2019, patients with OSA (apnea-hypopnea index $\geq 5$ ) treated using a PAP device for $\geq 1$ month were included. They were classified as belonging to the pre-insurance (PI) group (having started PAP before July 2018) or the NHI group (having received a PAP reimbursement by the NHI service). We collected and analyzed medical records and PAP use information for between-group comparisons of compliance. We defined compliance as the percentage of usage days, the percentage of days with usage for $\geq 4$ night hours, and average daily usage hours.

Results. We included 146 and 100 patients in the PI and NHI groups, respectively. Automatic PAP mode and NHI were independent predictors of compliance B at the 3- and 9-month follow-up points. The NHI group showed significantly higher compliance A at 3, but not 9 months. For compliance B, the NHI group showed significantly higher compliance than the PI group at 1 month and 3 months, but not at 9 months. Compared with the PI group, the NHI group showed significantly higher compliance $\mathrm{C}$ only at 3 months.

Conclusion. The NHI has positively affected PAP therapy in patients with OSA. Insurance policy may affect compliance within the first 3 months of PAP therapy.

Keywords. National Health Insurance; Positive Airway Pressure; Compliance; Obstructive Sleep Apnea

\section{INTRODUCTION}

Since positive airway pressure (PAP) was first introduced in the 1980s, it has become the most effective treatment for patients

\footnotetext{
- Received November 30, 2020

Revised January 27, 2021

Accepted February 5, 2021

- Corresponding author: Yoosam Chung

Department of Otorhinolaryngology-Head and Neck Surgery, Asan Medical Center, University of Ulsan College of Medicine, 88 Olympic-ro 43-gil, Songpa-gu, Seoul 05505, Korea

Tel: +82-2-3010-3716, Fax: +82-2-489-2773

E-mail: yschung@amc.seoul.kr
}

with moderate to severe obstructive sleep apnea (OSA) [1]. PAP maintains upper airway patency by acting as a pneumatic splint during sleep, which reduces the number of respiratory events and improves outcomes, including daytime sleepiness, cognitive performance, blood pressure, glucose control, cardiovascular status, quality of life, and mortality [2-5]. The PAP device should be regularly used to achieve these benefits [6,7].A widely recognized definition of good compliance to PAP therapy is PAP device usage for an average of 4 hours per night for $\geq 70 \%$ of the monitoring days [7]. Cost-related issues are significant barriers to PAP compliance that are directly affected by the national insurance coverage system applied to PAP therapy [8-10]. In South Korea

Copyright $\odot 2022$ by Korean Society of Otorhinolaryngology-Head and Neck Surgery

This is an open-access article distributed under the terms of the Creative Commons Attribution Non-Commercial License (https://creativecommons.org/licenses/by-nc/4.0)

which permits unrestricted non-commercial use, distribution, and reproduction in any medium, provided the original work is properly cited. 
(hereafter, Korea), before July 2018, patients with OSA requiring PAP therapy had to purchase or rent the PAP device at their own expense. In July 2018, National Health Insurance (NHI) coverage for polysomnography (PSG) and PAP was introduced in Korea. Specifically, patients who meet certain criteria in terms of the apnea-hypopnea index (AHI), as well as comorbidities related to sleep apnea, have their PAP rental fee reimbursed by the NHI. Previously, the PAP rental fee was approximately 330,000 won (\$292) a month; however, with insurance coverage, it has dropped to between 15,200 (\$13) and 25,200 won (\$21). According to the insurance policy, the PAP prescription can be extended only when a patient shows good compliance ( $\geq 21$ days of device usage for a minimum of 4 hours per night for 30 consecutive days) during the first 90 days. Since the prescription is available for up to 6 months, patients with OSA are required to have a doctor's appointment at least once every 6 months to maintain the reimbursement.

Between 2006 and 2018, PAP compliance in Korea ranged from $20 \%$ to $60 \%$, corresponding to a non-adherent level [1114]. With the introduction of NHI coverage for PAP therapyaccompanied by a reduction of costs for PAP devices, as well as an increased need for regular hospital visits-PAP compliance in Korea is expected to increase.

This study aimed to evaluate the effect of NHI coverage for PAP therapy on PAP compliance in Korea. This offers a good opportunity to discuss whether the current NHI policy is adequately supporting patients with OSA with PAP therapy.

\section{MATERIALS AND METHODS}

This study was approved by the Institutional Review Board of Asan Medical Center (IRB No. 2020-0007) and informed consent was waived.

We retrospectively reviewed the medical records of adult patients ( $\geq 18$ years) diagnosed with OSA who had started PAP treatment for $\geq 1$ month at the Asan Medical Center between

\section{H I G H L I}

- This study aimed to assess the effect of National Health Insurance (NHI) coverage on positive airway pressure (PAP) device compliance in patients with obstructive sleep apnea (OSA).

- The auto-adjusting mode and NHI coverage were independent predictors of PAP compliance.

- The NHI group showed significantly higher compliance at 1 and 3, but not 9 months.

- The NHI group was more likely to be adherent and less likely to be lost to follow-up at 9 months.

- NHI coverage has positively affected PAP therapy in patients with OSA.
January 2011 and September 2019. OSA was diagnosed using a full-night attended in-laboratory PSG. The PSG settings included continuous recording of the electroencephalogram, electrooculogram, electromyogram of the mentalis and anterior tibialis, electrocardiogram, thoracic-abdominal motion, oronasal thermistor, nasal pressure transducer, oxygen saturation and body position. The results of all data were analyzed by a trained technician using a high resolution monitor and were confirmed by a physician who is belong to sleep laboratory. The diagnosis of OSA was confirmed if the AHI $\geq 5$ in a patient with one or more symptoms of OSA (snoring, sleep apnea, daytime sleepiness, nonrestorative sleep, fatigue, or insomnia) or with comorbidities such as hypertension, type 2 diabetes mellitus, stroke, congestive heart failure, atrial fibrillation, coronary artery disease, mood disorder, or cognitive dysfunction. Patients with an AHI $\geq 15$ were also diagnosed OSA regardless of the presence of associated symptoms or comorbidities. We excluded patients with a history of sleep surgery or previous PAP usage. Consequently, 246 patients were included and classified into the pre-insurance (PI) group (patients who started PAP at their own expense before July 2018) and the NHI group (patients who were offered PAP reimbursement by the NHI service). All patients in the PI group purchased the PAP devices from their out-of-pocket expenses from the start of PAP therapy. Patients in both PI and NHI groups could choose which company's model to use at their own discretion, among ResMed, Philips, and Fisher \& Paykel. The mode of device was selected as per the following process: If the in-laboratory manual PAP titration was successfully performed, both the fixed-pressure continuous PAP (CPAP) mode and the autoadjusting positive airway pressure (APAP) mode were offered based on the titration results for more than ten consecutive days each, during the first month. The mode that achieved better compliance was selected for long-term prescription. If the compliance result was similar, the mode was chosen by the patients. If manual titration failed or was delayed, the APAP wide range was prescribed from the beginning and the pressure level was gradually adjusted based on the 90th or 95th percentile pressure recorded on the usage report. Given the rapid increase in the number of patients with sleep apnea from July 2018, there was a delay in the waiting time for the in-laboratory PAP titration. Furthermore, there was a time limitation for PAP therapy as the therapy needed to be started within 1 year of the PSG in order for the costs to be covered by the NHI. Therefore, we occasionally prescribed APAP without titration in the NHI group. We evaluated baseline data, including demographic characteristics, comorbidities, Epworth sleepiness scores [15], titration results, PSG measurements, and mode of the device determined at the first month (CPAP or APAP). Data regarding usage, including 90th or 95th percentile pressure, residual AHI, and usage hours were obtained from the device at 1,3, and 9 months after starting the PAP therapy. This study defined PAP compliance as A (percentage of used days over the monitoring days), B (percent- 
age of days used for $\geq 4$ night hours over the monitoring days), and $\mathrm{C}$ (average hours of daily usage). Between-group comparisons of compliance were performed at three follow-up time points (1, 3, and 9 months). Since the pressure changed several times during the first month, we could not determine the reliable average usage time. Statistical analyses were performed using STATA ver. 14.0 (Stata Corp., College Station,TX, USA). Between-group differences in categorical and continuous variables were performed using the Chi-square test and a two-sample independent $t$-test, respectively. A multivariate logistic regression analysis with stepwise selection of covariates was used to identify factors independently associated with compliance $\mathrm{B}$, as the compliance $\mathrm{B}$ indicates the standard definition of PAP adherence. Confounding factors were adjusted using multivariate linear regression analysis for between-group comparison of the compliance.

\section{RESULTS}

This study included 246 patients with OSA (146 and 100 patients in the PI and NHI groups, respectively). There were no significant between-group differences in any baseline characteristics, except in the PAP titration rate (proportion of patients who underwent in-laboratory titration among the total patients in each group) (Table 1). Table 2 shows differences between the adherent group (compliance $\mathrm{B} \geq 70 \%$ ) and the non-adherent group (compliance B $<70 \%$ or lost to follow-up). Patients in the adherent group were significantly older $(P=0.003)$ than their counterparts in the non-adherent group, and the non-adherent group contained a significantly higher proportion of those using the APAP mode and NHI than the non-adherent group at both 3 and 9 months (all $P<0.001$ ). There were significantly more patients with hypertension in the adherent group at 3 months, but no significant difference was found at 9 months. The proportion of patients who underwent overnight in-laboratory manual titration was significantly higher in the non-adherent group at both 3 and 9 months. Univariate analysis showed that PAP compliance (compliance B) for the first 3 months was associated with age, hypertension, PAP titration, APAP mode, and NHI coverage. Subsequent multivariate analysis showed that APAP mode $(P=$ $0.009)$ and NHI coverage $(P<0.001)$ were significantly related to compliance B (Table 3). Regarding the next 6 months, when compliance was evaluated at the 9-month follow-up point, univariate and multivariate analysis showed that sex $(P=0.029)$, APAP mode $(P=0.005)$, and NHI $(P=0.015)$ were independent predictors of compliance B (Table 3). Table 4 shows compliance in both groups analyzed with adjustment for confounding factors. At all three time points, the NHI group showed higher compliance than the PI group. The NHI group showed a significantly higher level of compliance A at 3 months $(P=0.002)$. Further, there was a significant between-group difference in compliance B at 1 month $(P=0.004)$ and 3 months $(P<0.001)$, but not at
Table 1. Baseline characteristics $(n=246)$

\begin{tabular}{lccr}
\hline Factor & Pl group $(n=146)$ & NHI group $(n=100)$ & $P$-value \\
\hline Age $(\mathrm{yr})$ & $50.20 \pm 11.04$ & $52.50 \pm 12.12$ & 0.124 \\
Sex & & & 0.379 \\
Male & $121(82.9)$ & $87(87.0)$ & \\
Female & $25(17.1)$ & $13(13.0)$ & \\
BMI (kg/m $\left.{ }^{2}\right)$ & $27.10 \pm 4.18$ & $26.41 \pm 3.09$ & 0.161 \\
Comorbidity & & & \\
HTN & $58(39.7)$ & $29(29.0)$ & 0.084 \\
DM & $16(11.0)$ & $11(11.0)$ & 0.992 \\
Smoking & $37(25.3)$ & $17(17.0)$ & 0.120 \\
CVD & $14(9.6)$ & $9(9.0)$ & 0.876 \\
Stroke & $1(0.7)$ & $2(2.0)$ & 0.568 \\
NSD & $41(28.1)$ & $39(39.0)$ & 0.073 \\
ESS & $9.43 \pm 5.14$ & $8.97 \pm 4.74$ & 0.526 \\
PSG measurement & & & \\
AHI (hr) & $44.02 \pm 21.68$ & $45.12 \pm 20.39$ & 0.690 \\
RDI (hr) & $46.99 \pm 20.12$ & $46.98 \pm 19.62$ & 0.997 \\
TAl (hr) & $40.25 \pm 18.50$ & $40.52 \pm 17.78$ & 0.910 \\
PLMI (hr) & $4.74 \pm 10.80$ & $3.49 \pm 12.82$ & 0.418 \\
TST (min) & $328.40 \pm 47.63$ & $328.59 \pm 42.53$ & 0.975 \\
ODI (hr) & $38.43 \pm 23.19$ & $39.49 \pm 21.94$ & 0.724 \\
Titration & $141(96.6)$ & $73(73.0)$ & $<0.001$ \\
Mode & & & 0.135 \\
CPAP & $74(50.7)$ & $41(41.0)$ & \\
APAP & $72(49.3)$ & $59(59.0)$ & \\
\hline Valusare & & & \\
\hline
\end{tabular}

Values are presented as mean \pm standard deviation or number (\%).

$\mathrm{PI}$, pre-insurance; NHI, National Health Insurance; BMI, body mass index; HTN, hypertension; DM, diabetes mellitus; CVD, cardiovascular disease; NSD, nasal septal deviation; ESS, Epworth sleepiness score; PSG, polysomnography; AHI, apnea-hypopnea index; RDI, respiratory distress index; TAI, total arousal index; PLMI, periodic limb movement index; TST, total sleep time; ODI, oxygen desaturation index; CPAP, continuous positive airway pressure; APAP, auto-adjusting positive airway pressure.

9 months. For compliance $\mathrm{C}$, the 3-month compliance was significantly higher in the NHI group $(P<0.001)$; however, there was no between-group difference at 9 months. The proportion of follow-up and adherent patients is shown in Fig. 1. Both groups showed a progressively decreasing number of patients who continued to receive follow-up, but the proportion of patients lost to follow-up in the NHI group (18\%) was lower than that in the PI group (34\%). With adherence defined as a compliance B level of $\geq 70 \%$, at 9 months, the adherence rate in the NHI group dropped to $47 \%$, which was more than double that in the PI group $(22 \%)$.

\section{DISCUSSION}

With the implementation of NHI coverage of PSG and PAP therapy, there was a significant increase in public awareness regarding sleep apnea disease. According to the data from the Korean NHI Service, the number of patients undergoing PSG has al- 
Table 2. Comparisons of adherent and non-adherent groups at 3 and 9 months

\begin{tabular}{|c|c|c|c|c|c|c|}
\hline \multirow{2}{*}{ Factor } & \multicolumn{3}{|c|}{$3 \mathrm{mo}$} & \multicolumn{3}{|c|}{$9 \mathrm{mo}$} \\
\hline & Adherent $(n=110)$ & Non-adherent $(n=136)$ & $P$-value & Adherent $(n=99)$ & Non-adherent $(n=147)$ & $P$-value \\
\hline Age (yr) & $53.57 \pm 11.24$ & $49.16 \pm 11.41$ & 0.003 & $53.74 \pm 10.80$ & $49.38 \pm 11.70$ & 0.003 \\
\hline Sex & & & 0.480 & & & 0.057 \\
\hline Male & $95(86.4)$ & $113(83.1)$ & & 89 (89.9) & $119(81.0)$ & \\
\hline Female & $15(13.6)$ & $23(16.9)$ & & $10(10.1)$ & $28(19.0)$ & \\
\hline $\operatorname{BMl}\left(\mathrm{kg} / \mathrm{m}^{2}\right)$ & $27.61 \pm 3.58$ & $26.98 \pm 3.94$ & 0.446 & - & - & 0.307 \\
\hline \multicolumn{7}{|l|}{ Comorbidity } \\
\hline HTN & $48(43.6)$ & $39(28.7)$ & 0.015 & $40(40.4)$ & $47(32.0)$ & 0.175 \\
\hline DM & $15(13.6)$ & $12(8.8)$ & 0.230 & $11(11.1)$ & $16(10.9)$ & 0.956 \\
\hline Smoking & $25(22.7)$ & $29(21.3)$ & 0.791 & $23(23.2)$ & $31(21.1)$ & 0.690 \\
\hline CVD & $11(10)$ & $12(8.8)$ & 0.753 & $5(5.1)$ & $18(12.2)$ & 0.057 \\
\hline Stroke & $2(1.8)$ & $1(0.7)$ & 0.442 & $1(1.0)$ & $2(1.4)$ & 0.806 \\
\hline NSD & $36(32.7)$ & $44(32.4)$ & 0.982 & $35(35.4)$ & $45(30.6)$ & 0.458 \\
\hline ESS & $9.43 \pm 5.14$ & $8.97 \pm 4.74$ & 0.370 & $8.56 \pm 4.29$ & $9.69 \pm 5.34$ & 0.114 \\
\hline \multicolumn{7}{|c|}{ PSG measurement } \\
\hline $\mathrm{AHI}(\mathrm{hr})$ & $45.73 \pm 21.03$ & $45.43 \pm 21.22$ & 0.399 & $46.51 \pm 21.95$ & $43.08 \pm 20.51$ & 0.213 \\
\hline RDI (hr) & $47.42 \pm 20.27$ & $46.62 \pm 19.61$ & 0.755 & $47.86 \pm 21.53$ & $46.39 \pm 18.73$ & 0.572 \\
\hline TAl (hr) & $39.32 \pm 18.27$ & $41.22 \pm 18.09$ & 0.422 & $40.12 \pm 19.15$ & $40.53 \pm 17.51$ & 0.863 \\
\hline PLMI (hr) & $4.04 \pm 12.93$ & $4.35 \pm 10.57$ & 0.838 & $3.48 \pm 10.83$ & $4.72 \pm 12.26$ & 0.423 \\
\hline TST (min) & $329.26 \pm 45.64$ & $327.83 \pm 45.52$ & 0.807 & $326.19 \pm 39.80$ & $330.05 \pm 49.09$ & 0.520 \\
\hline ODI (hr) & $40.31 \pm 22.74$ & $22.74 \pm 22.54$ & 0.378 & $40.81 \pm 23.09$ & $37.54 \pm 22.28$ & 0.275 \\
\hline Titration & $90(81.8)$ & $124(91.2)$ & 0.036 & $80(80.8)$ & $134(91.2)$ & 0.018 \\
\hline Mode & & & $<0.001$ & & & $<0.001$ \\
\hline CPAP & $35(31.8)$ & $80(58.8)$ & & 29 (29.3) & $86(58.5)$ & \\
\hline APAP & 75 (68.2) & $56(41.2)$ & & $70(70.7)$ & $61(41.5)$ & \\
\hline $\mathrm{NHI}$ & $62(56.4)$ & $38(27.9)$ & $<0.001$ & $56(56.6)$ & 44 (29.9) & $<0.001$ \\
\hline
\end{tabular}

Values are presented as mean \pm standard deviation or number $(\%)$.

BMI, body mass index; HTN, hypertension; DM, diabetes mellitus; CVD, cardiovascular disease; NSD, nasal septal deviation; ESS, Epworth sleepiness score; PSG, polysomnography; AHI, apnea-hypopnea index; RDI, respiratory distress index; TAI, total arousal index; PLMI, periodic limb movement index; TST, total sleep time; ODI, oxygen desaturation index; CPAP, continuous positive airway pressure; APAP, auto-adjusting positive airway pressure; NHI, National Health Insurance.

most tripled from 2,600 in July 2018 to 6,205 in May 2019. The reduction of the personal economic burden by insurance coverage has led to more patients opting for PAP therapy. However, with the increased demand from patients with sleep apnea, the financial burden on the NHI has increased. Therefore, there is a need to determine whether and how NHI coverage has significantly affected PAP therapy. Our findings indicate that NHI coverage has positively influenced the PAP use pattern. At 3 months, the NHI group showed significantly higher compliance A and B than the PI group. This indicates that the NHI group used PAP devices more often and efficiently than the PI group. However, there was no significant between-group difference in any definitions of compliance (A, B, and C) at 9 months. The fact that the current insurance policy requires good compliance only for the first 90 days to maintain the reimbursement on PAP therapy might explain the difference between the 3 - and 9-month results. Therefore, the insurance policy itself, in addition to the cost reduction benefit, appears to increase PAP compliance during the first 3 months. The Centers for Medicare and Medicaid Services (CMS) of the United States of America, which have provided reimbursement for PAP since 2008, also evaluate compliance for the first 3 months in anticipation of long-term PAP usage and benefits. However, it has been argued that the CMS criteria for early compliance can limit the benefits of PAP therapy in patients who might become adherent after 3 months. According to a study by Naik et al. [16], seven of 23 (30.4\%) initially non-adherent (using CMS criteria) participants became adherent during the remainder of the year, indicating that PAP nonadherence during the first 3 months was predictive of further nonadherence in only $69.6 \%$ of cases.

Notably, we found that the NHI group maintained a compliance level of $70 \%$ at 9 months, which corresponds to a good compliance level. This level is higher than that reported by previous Korean studies, as well as that of the PI group in this study [11-14]. There was no significant between-group difference in compliance B at 9 months $(P=0.085)$; however, this study had a small sample size, and larger sample sizes might yield significant findings. Moreover, since initial PAP use has been shown to predict PAP compliance for up to 1 year [17,18], the high compliance during the first 3 months could have led to increased com- 
Table 3. Predictors of PAP compliance based on compliance B at 3 and 9 months

\begin{tabular}{|c|c|c|c|c|c|c|c|c|}
\hline \multirow{3}{*}{ Predictor } & \multicolumn{4}{|c|}{$3 \mathrm{mo}$} & \multicolumn{4}{|c|}{$9 \mathrm{mo}$} \\
\hline & \multicolumn{2}{|c|}{ Univariate analysis } & \multicolumn{2}{|c|}{ Multivariate analysis } & \multicolumn{2}{|c|}{ Univariate analysis } & \multicolumn{2}{|c|}{ Multivariate analysis } \\
\hline & OR $(95 \% \mathrm{Cl})$ & $P$-value & OR $(95 \% \mathrm{Cl})$ & $P$-value & OR $(95 \% \mathrm{Cl})$ & $P$-value & OR $(95 \% \mathrm{Cl})$ & $P$-value \\
\hline Age & $1.03(1.01-1.06)$ & 0.007 & $1.03(0.99-1.06)$ & 0.052 & $1.02(0.99-1.05)$ & 0.108 & & \\
\hline \multicolumn{9}{|l|}{ Sex } \\
\hline Male & $1.30(0.62-2.73)$ & 0.495 & & & $2.65(1.14-6.20)$ & 0.024 & $2.74(1.11-6.75)$ & 0.029 \\
\hline Female & Reference & & & & Reference & & Reference & \\
\hline $\mathrm{BMl}$ & $0.98(0.91-1.06)$ & 0.623 & & & $0.94(0.86-1.03)$ & 0.190 & & \\
\hline \multicolumn{9}{|l|}{ Comorbidity } \\
\hline HTN & $1.79(1.02-3.14)$ & 0.042 & $1.97(1.05-3.69)$ & 0.035 & $1.11(0.60-2.07)$ & 0.732 & & \\
\hline DM & $1.52(0.65-3.54)$ & 0.337 & & & $1.20(0.44-3.25)$ & 0.725 & & \\
\hline Smoking & $1.06(0.56-2.02)$ & 0.856 & & & $1.10(0.53-2.26)$ & 0.802 & & \\
\hline CVD & $0.87(0.37-2.07)$ & 0.753 & & & $0.34(0.11-1.04)$ & 0.059 & $0.30(0.09-1.01)$ & 0.051 \\
\hline Stroke & $1.94(0.17-21.77)$ & 0.589 & & & $0.74(0.05-12.11)$ & 0.836 & & \\
\hline NSD & $1.03(0.58-1.82)$ & 0.919 & & & $1.21(0.64-2.30)$ & 0.556 & & \\
\hline ESS & $0.98(0.92-1.04)$ & 0.516 & & & $0.94(0.88-1.01)$ & 0.094 & & \\
\hline \multicolumn{9}{|c|}{ PSG measurement } \\
\hline $\mathrm{AHI}$ & $1.01(0.99-1.02)$ & 0.419 & & & $1.01(0.99-1.03)$ & 0.187 & & \\
\hline $\mathrm{RDI}$ & $1.00(0.99-1.02)$ & 0.750 & & & $1.01(0.99-1.02)$ & 0.472 & & \\
\hline TAl & $0.99(0.98-1.01)$ & 0.586 & & & $1.00(0.98-1.02)$ & 0.937 & & \\
\hline PLMI & $0.99(0.97-1.02)$ & 0.784 & & & $0.99(0.96-1.02)$ & 0.392 & & \\
\hline TST & $1.00(0.99-1.01)$ & 0.840 & & & $0.99(0.99-1.01)$ & 0.798 & & \\
\hline ODI & $1.00(0.99-1.02)$ & 0.434 & & & $1.01(0.99-1.02)$ & 0.222 & & \\
\hline Titration & $0.32(0.13-0.79)$ & 0.013 & $0.65(0.23-1.80)$ & 0.406 & $0.24(0.08-0.74)$ & 0.013 & $0.49(0.13-1.81)$ & 0.281 \\
\hline \multicolumn{9}{|l|}{ Mode } \\
\hline CPAP & Reference & & Reference & & Reference & & Reference & \\
\hline APAP & $2.14(1.23-3.73)$ & 0.007 & $2.26(1.22-4.17)$ & 0.009 & $2.69(1.43-5.04)$ & 0.002 & $2.71(1.35-5.43)$ & 0.005 \\
\hline Mean pressure & $0.99(0.87-1.12)$ & 0.840 & & & $0.94(0.81-1.08)$ & 0.375 & & \\
\hline Residual AHI & $1.01(0.89-1.13)$ & 0.931 & & & $1.02(0.87-1.21)$ & 0.780 & & \\
\hline \multicolumn{9}{|l|}{ Insurance } \\
\hline $\mathrm{PI}$ & Reference & & Reference & & Reference & & Reference & \\
\hline $\mathrm{NHI}$ & $2.99(1.71-5.23)$ & $<0.001$ & $3.12(1.66-5.85)$ & $<0.001$ & $2.55(1.37-4.77)$ & 0.003 & $2.39(1.18-4.81)$ & 0.015 \\
\hline
\end{tabular}

PAP, positive airway pressure; OR, odds ratio; Cl, confidence interval; BMI, body mass index; HTN, hypertension; DM, diabetes mellitus; CVD, cardiovascular disease; NSD, nasal septal deviation; ESS, Epworth sleepiness score; PSG, polysomnography; AHI, apnea-hypopnea index; RDI, respiratory distress index; TAI, total arousal index; PLMI, periodic limb movement index; TST, total sleep time; ODI, oxygen desaturation index; CPAP, continuous positive airway pressure; APAP, auto-adjusting positive airway pressure; PI, pre-insurance; NHI, National Health Insurance.

Table 4. Between-group comparison of compliance at 1, 3, and 9 months

\begin{tabular}{|c|c|c|c|c|c|c|c|c|c|}
\hline \multirow[b]{2}{*}{ Compliance } & \multicolumn{3}{|c|}{$1 \mathrm{mo}$} & \multicolumn{3}{|c|}{$3 \mathrm{mo}$} & \multicolumn{3}{|c|}{$9 \mathrm{mo}$} \\
\hline & $\begin{array}{l}\text { Pl group } \\
(n=146)\end{array}$ & $\begin{array}{l}\mathrm{NHI} \text { group } \\
(\mathrm{n}=100)\end{array}$ & $P$-value & $\begin{array}{l}\text { Pl group } \\
(n=116)\end{array}$ & $\begin{array}{l}\mathrm{NHI} \text { group } \\
(\mathrm{n}=95)\end{array}$ & $P$-value & $\begin{array}{l}\text { Pl group } \\
(n=96)\end{array}$ & $\begin{array}{l}\text { NHI group } \\
(n=82)\end{array}$ & $P$-value \\
\hline Compliance $\mathrm{A}^{\mathrm{a})}(\%)$ & $90.03 \pm 1.18$ & $90.42 \pm 1.99$ & 0.870 & $80.36 \pm 1.54$ & $88.13 \pm 1.77$ & 0.002 & $83.09 \pm 2.13$ & $81.89 \pm 2.27$ & 0.702 \\
\hline Compliance $\mathrm{B}^{\mathrm{b})}(\%)$ & $65.99 \pm 2.06$ & $78.22 \pm 3.55$ & 0.004 & $58.17 \pm 2.23$ & $74.88 \pm 2.56$ & $<0.001$ & $63.85 \pm 2.58$ & $70.39 \pm 2.75$ & 0.085 \\
\hline Compliance $\mathrm{C}^{\mathrm{c})}(\mathrm{hr})$ & & & & $4.20 \pm 0.14$ & $5.05 \pm 0.17$ & $<0.001$ & $4.52 \pm 0.17$ & $4.77 \pm 0.18$ & 0.323 \\
\hline
\end{tabular}

Values are presented as mean \pm standard deviation.

$\mathrm{Pl}$, pre-insurance; $\mathrm{NHI}$, National Health Insurance.

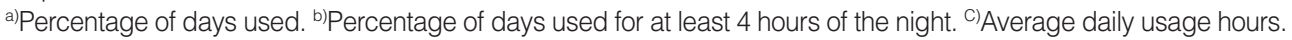

pliance for the subsequent $\geq 6$ months. Consistent with our findings, a long-term prospective study by Billings and Kapur [19] reported a higher initial adherence with the CMS policy than with the clinic-only policy. Specifically, the CMS policy had an $11 \%$ higher adherence rate than the control group after 5 years.
Another notable finding was a decrease and increase in the proportion of patients lost to follow-up and maintaining good compliance, respectively, after NHI implementation. The insurance policy dictates that patients must visit the outpatient clinic within every 6 months to renew the PAP prescription. This regu- 


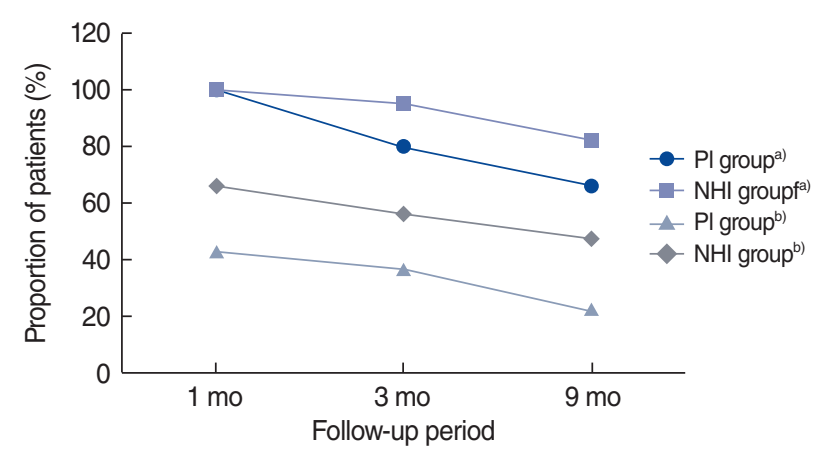

Fig. 1. Proportions of follow-up and adherent patients at 1, 3, and 9 months. PI, pre-insurance; NHI, National Health Insurance. ${ }^{a)}$ Number of follow-up patients out of total number of group patients. ${ }^{\text {b) Number }}$ of adherent patients out of total number of group patients.

lar follow-up allows doctors to encourage patients to discuss their difficulties with using PAP, provide repeated education to improve patients' willingness to use the device, and control the PAP pressure to match the patients' condition precisely [20,21].

In addition to NHI, the APAP mode was shown to be a significant predictor of compliance by multivariate analysis. As more patients in the NHI group used the APAP mode to adjust the pressure instead of conducting a titration, the NHI group showed a higher proportion of patients who continued to use the APAP mode. The efficacy, acceptance, and compliance of APAP compared with CPAP remain unclear; however, several studies have indicated that patients tend to prefer the APAP mode [22,23]. As reported by Randerath et al. [24], we assume that the pressure flexibility allowed by the APAP mode provides comfort to patients, thereby increasing acceptance and compliance.

According to previous studies on comorbidities and long-term compliance, hypertension is not an important predictor of longterm compliance; however, recently, Rafael-Palou et al. [25] reported that hypertension was closely related to compliance at 1-3 months [26,27]. Our study confirmed these findings through between-group comparisons and multivariate analysis. The effect of in-laboratory manual titration is unclear, with some studies showing reduced PAP use without titration [28], while others reported no difference in the titration rate between compliant and non-compliant groups [29]. Unlike previous reports, the titration rate was slightly lower in the adherent group in this study. This finding could reflect the fact that the proportion of patients without titration in the NHI group was higher than that in the PI group, not that titration itself had a negative effect on compliance. This was confirmed by our results showing that titration was not a significant predictor of PAP compliance when controlling for other factors such as NHI and the PAP mode.

This study has several limitations. First, the short follow-up period meant that it was not possible to analyze a large sample or to evaluate long-term compliance. Specifically, the study period (data collection) was $<2$ years after the implementation of
NHI coverage for PAP; therefore, a 9-month follow-up period was the longest period that could be studied. Second, we did not collect socioeconomic data, including income level, employment status, and education, which could affect compliance [30]. Third, since this study was only conducted at a tertiary center, our findings could have been affected by referral bias, and the retrospective design of this study implies a risk of selection bias. Finally, the generalizability of the results is also limited, since the findings may apply only to Korea.

Nevertheless, this is the first study to investigate the influence of NHI coverage on PAP therapy in Korea. Future prospective multicenter studies are needed to verify the long-term efficacy of NHI coverage on PAP therapy. The NHI policy has been beneficial to patients with sleep apnea on PAP therapy by enhancing efficient device use and regular follow-up visits. The 90-day initial compliance-testing period could affect both early and long-term compliance. Modification of the NHI policy could further affect PAP compliance. This study could be a useful reference for future studies on the adequacy of the revised NHI policy in Korea, as well as to other countries considering implementation of NHI coverage for PAP therapy.

\section{CONFLICT OF INTEREST}

No potential conflict of interest relevant to this article was reported.

\section{ORCID}

$\begin{array}{ll}\text { Woori Choi } & \text { https://orcid.org/0000-0001-7532-4462 } \\ \text { Mirye Bae } & \text { https://orcid.org/0000-0002-5683-2178 } \\ \text { Yoosam Chung } & \text { https://orcid.org/0000-0002-8866-5415 }\end{array}$

\section{AUTHOR CONTRIBUTIONS}

Conceptualization: YC. Data curation:WC, MB. Formal analysis: WC. Methodology: YC, WC. Project administration: WC. Visualization: WC. Writing-original draft: Woori Choi. Writing-review \& editing: YC,WC.

\section{REFERENCES}

1. Sullivan CE, Issa FG, Berthon-Jones M, Eves L. Reversal of obstructive sleep apnoea by continuous positive airway pressure applied through the nares. Lancet. 1981 Apr;1(8225):862-5.

2. McGinley BM, Schwartz AR, Schneider H, Kirkness JP, Smith PL, Patil SP. Upper airway neuromuscular compensation during sleep is defective in obstructive sleep apnea. J Appl Physiol (1985). 2008 Jul;105(1):197-205. 
3. Antic NA, Catcheside P, Buchan C, Hensley M, Naughton MT, Rowland $\mathrm{S}$, et al. The effect of CPAP in normalizing daytime sleepiness, quality of life, and neurocognitive function in patients with moderate to severe OSA. Sleep. 2011 Jan;34(1):111-9.

4. McEvoy RD, Antic NA, Heeley E, LuoY, Ou Q, Zhang X, et al. CPAP for prevention of cardiovascular events in obstructive sleep apnea. $\mathrm{N}$ Engl J Med. 2016 Sep;375(10):919-31.

5. Lisan Q, Van Sloten T, Marques Vidal P, Haba Rubio J, Heinzer R, Empana JP.Association of positive airway pressure prescription with mortality in patients with obesity and severe obstructive sleep apnea: the sleep heart health study. JAMA Otolaryngol Head Neck Surg. 2019 Jun;145(6):509-15.

6. WeaverTE, Maislin G, Dinges DF, Bloxham T, George CF, Greenberg $\mathrm{H}$, et al. Relationship between hours of CPAP use and achieving normal levels of sleepiness and daily functioning. Sleep. 2007 Jun;30(6): 711-9.

7. Kribbs NB, Pack AI, Kline LR, Smith PL, Schwartz AR, Schubert NM, et al. Objective measurement of patterns of nasal CPAP use by patients with obstructive sleep apnea. Am Rev Respir Dis. 1993 Apr; 147(4):887-95.

8. Simon-Tuval T, Reuveni H, Greenberg-Dotan S, Oksenberg A, Tal A, Tarasiuk A. Low socioeconomic status is a risk factor for CPAP acceptance among adult OSAS patients requiring treatment. Sleep. 2009 Apr;32(4):545-52.

9. Gulati A, Ali M, Davies M, Quinnell T, Smith I. A prospective observational study to evaluate the effect of social and personality factors on continuous positive airway pressure (CPAP) compliance in obstructive sleep apnoea syndrome. BMC Pulm Med. 2017 Mar;17(1):56.

10. Leemans J, Rodenstein D, Bousata J, Mwenge GB. Impact of purchasing the CPAP device on acceptance and long-term adherence: a Belgian model. Acta Clin Belg. 2018 Feb;73(1):34-9.

11. Han EK, Yoon IY, Chung SH. The compliance and effect of CPAP in obstructive sleep apnea syndrome. Sleep Med Psychophysiol. 2006 Dec;13(2):52-8.

12. Lee SM, Lee YJ, Kim JH. Common side effects and compliance with nasal continuous positive airway pressure in Korean OSA patients: short-term follow up. J Korean Sleep Res Soc. 2010 Jun;7(1):1-7.

13. KIM MJ, Kim MJ, Bae SH, Park CH, Kim DK. Predictors of adherence with positive airway pressure treatment in patients with obstructive sleep apnea in Korean. J Rhinol. 2015 Nov;22(2):89-95.

14. Kim SL, Kim JA, Kim DS, Jo MG, Kim SD, Cho KS. Effect of doctor and device manager on adherence with positive airway pressure therapy in obstructive sleep apnea patients. J Rhinol. 2018 May; 25(1):26-31.

15. Johns MW. A new method for measuring daytime sleepiness: the Epworth sleepiness scale. Sleep. 1991 Dec;14(6):540-5.

16. Naik S, Al-Halawani M, Kreinin I, Kryger M. Centers for Medicare and Medicaid Services positive airway pressure adherence criteria may limit treatment to many Medicare beneficiaries. J Clin Sleep Med. 2019 Feb;15(2):245-51.
17. Van Ryswyk E, Anderson CS, Antic NA, Barbe F, Bittencourt L, Freed R, et al. Predictors of long-term adherence to continuous positive airway pressure in patients with obstructive sleep apnea and cardiovascular disease. Sleep. 2019 Oct;42(10):zsz152.

18. Popescu G, Latham M, AllgarV, Elliott MW. Continuous positive airway pressure for sleep apnoea/hypopnoea syndrome: usefulness of a 2 week trial to identify factors associated with long term use. Thorax. 2001 Sep;56(9):727-33.

19. Billings ME, Kapur VK. Medicare long-term CPAP coverage policy: a cost-utility analysis. J Clin Sleep Med. 2013 Oct;9(10):1023-9.

20. Ghrairi H, Khalfallah I, Abid N, Loukil M. Adherence to treatment with continuous positive airways pressure. Rev Mal Respir. 2018 May;35(5):531-7.

21. Sin DD, Mayers I, Man GC, Pawluk L. Long-term compliance rates to continuous positive airway pressure in obstructive sleep apnea: a population-based study. Chest. 2002 Feb;121(2):430-5.

22. Galetke W, Anduleit N, Richter K, Stieglitz S, Randerath WJ. Comparison of automatic and continuous positive airway pressure in a night-by-night analysis: a randomized, crossover study. Respiration. 2008 Mar;75(2):163-9.

23. Mulgrew AT, Cheema R, Fleetham J, Ryan CF, Ayas NT. Efficacy and patient satisfaction with autoadjusting CPAP with variable expiratory pressure vs standard CPAP: a two-night randomized crossover trial. Sleep Breath. 2007 Mar;11(1):31-7.

24. Randerath WJ, Schraeder O, GaletkeW, Feldmeyer F, Ruhle KH.Autoadjusting CPAP therapy based on impedance efficacy, compliance and acceptance. Am J Respir Crit Care Med. 2001 Mar;163(3 Pt 1): 652-7.

25. Rafael-Palou X, Turino C, Steblin A, Sanchez-de-la-Torre M, Barbe F, Vargiu E. Comparative analysis of predictive methods for early assessment of compliance with continuous positive airway pressure therapy. BMC Med Inform Decis Mak. 2018 Sep;18(1):81.

26. Campos-Rodriguez F, Martinez-Garcia MA, Reyes-Nunez N, Caballero-Martinez I, Almeida-Gonzalez CV, Catalan-Serra P, et al. Longterm continuous positive airway pressure compliance in females with obstructive sleep apnoea. Eur Respir J. 2013 Nov;42(5):1255-62.

27. Wohlgemuth WK, Chirinos DA, Domingo S, Wallace DM. Attempters, adherers, and non-adherers: latent profile analysis of CPAP use with correlates. Sleep Med. 2015 Mar;16(3):336-42.

28. Means MK, Edinger JD, Husain AM. CPAP compliance in sleep apnea patients with and without laboratory CPAP titration. Sleep Breath. 2004 Mar;8(1):7-14.

29. Lee CH, Leow LC, Song PR, Li H, Ong TH. Acceptance and adherence to continuous positive airway pressure therapy in patients with obstructive sleep apnea (OSA) in a Southeast Asian privately funded healthcare system. Sleep Sci. 2017 Apr-Jun;10(2):57-63.

30. Pandey A, Mereddy S, Combs D, Shetty S, Patel SI, Mashaq S, et al. Socioeconomic inequities in adherence to positive airway pressure therapy in population-level analysis. J Clin Med. 2020 Feb;9(2):442. 